


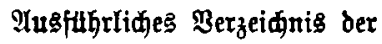
Buttentagløen Sammlung

\section{Beut/her Reidjs-}

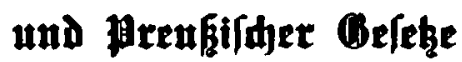

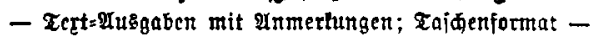
melde alle widtigeren (Sefeke in unbedingt $j^{4}=$ verläfigen (sefésestecten und in matergïltiger Beije erläutert enthält, befindet fich hinter bem Sađhregiłter. 


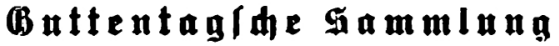 Hr. 8. Eeut/her lixidsgeletge. Hr. 8.

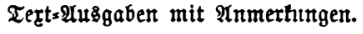

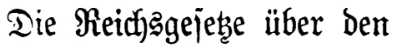 DInterftükuแ̣swof)nfik,}

in ber Jaffiung Der Nobelle vom 12. März 1894,

Die freiziigigkeit, Dent Erwerb und $\mathfrak{D e r l u f t}$ Der Bundeg- und Stantsangeljörigkeit, nebit ben

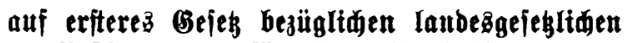
Befitinımungen jämtltđer Bunbeştaaten.

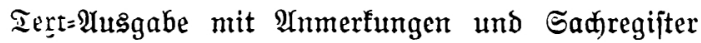
vort

\section{Dr. I. fereh,}

\section{Rait. (Seh. Regierumgsrat}

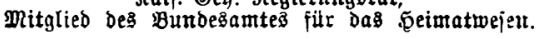

\section{Sequite, vermehrte und verbeñexte atuftage.}

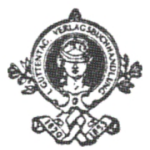

Berlin 1907.

J. Guttentag, BerIag

(3. nt. b. $\mathfrak{S}$. 
